\title{
Midazolam Enhances Mutant Huntingtin Protein Accumulation via Impairment of Autophagic Degradation In Vitro
}

\author{
Jiqian Zhang ${ }^{\mathrm{a}} \quad$ Wei Dai $^{\mathrm{a}} \quad$ Pengcheng Geng $^{\mathrm{a}} \quad$ Li Zhang $^{\mathrm{b}} \quad$ Qilian Tan $^{\mathrm{a}} \quad$ Dan Cheng $^{\mathrm{a}}$ \\ Pengfei Weic Zhilai Yang ${ }^{a}$ Lei Zhang ${ }^{a} \quad$ Erwei Gu ${ }^{a}$ Guanghong Xu \\ Chaozhao Liang ${ }^{\mathrm{b}}$ Xuesheng Liu ${ }^{\mathrm{a}}$ \\ aDepartment of Anesthesiology, the First Affiliated Hospital of Anhui Medical University, Hefei, \\ ${ }^{b}$ Department of Urology, the First Affiliated Hospital of Anhui Medical University, Hefei, 'School of Life \\ Sciences and Medical Center, University of Science and Technology of China, Hefei National Laboratory \\ for Physical Sciences at Microscale, Hefei, China
}

\section{Key Words}

Midazolam - Mutant huntingtin protein $(\mathrm{mHtt})$ - Polyglutamine diseases - Autophagy • Cathepsin D

\begin{abstract}
Background/Aims: Autophagy is a well-known pathway to "clean" the misfolded mutant huntingtin protein $(\mathrm{mHtt})$, which plays a considerable role in polyglutamine diseases. To date, there have been few studies of the choice of anesthetic during surgery in patients with polyglutamine diseases and evaluation of the effects and underlying mechanisms of anesthetics in these patients. Methods: GFP-Htt (Q74)-PC12 cells, which stably express green fluorescent protein-tagged $\mathrm{Htt}$ protein containing 74 glutamine repeating units, were used throughout this study. Cells were treated with $15 \mu \mathrm{M}$ midazolam and $100 \mathrm{mM}$ trehalose (positive control), and the induction of autophagy and autophagic degradation were assessed by detecting changes in autophagy-related proteins and substrates, and cell viability was assessed using the MTT assay. Overexpression of cathepsin D by plasmid transfection was used to restore midazolamimpaired autophagic degradation. Results: Midazolam increased intracellular mHtt levels in a time- and dose-dependent manner. Additionally, enhancing or blocking autophagic flux by trehalose or chloroquine could decrease or increase midazolam-induced $\mathrm{mHtt}$ elevation, respectively. Midazolam induced autophagy in the mTOR-dependent signaling pathway, but autophagic degradation was impaired, with a continuous rise in p62 and LC3 II levels and decrease in cathepsin D. However, overexpression of cathepsin D reversed the effects of midazolam. Midazolam led to a 20\% decrease in GFP-Htt (Q74)-PC12 cell viability, which could be abrogated by overexpression of cathepsin D. Conclusions: Midazolam increased $\mathrm{mHtt}$ levels and decreased Htt (Q74)-PC12 cell viability via impairment of autophagic degradation, which could be restored by overexpression of cathepsin D.




\section{Cellular Physiology Cell Physiol Biochem 2018;48:683-691 and Biochemistry Published online: July 19, $2018 \quad$\begin{tabular}{l|l} 
DOI: 10.1159/000491895 & $\begin{array}{l}\text { C) } 2018 \text { The Author(s). Published by S. Karger AG, Basel } \\
\text { www.karger.com/cpb }\end{array}$
\end{tabular}}

Zhang et al.: Midazolam Enhances Mutant Huntingtin Protein Accumulation

\section{Introduction}

Increasing evidence has demonstrated that accumulation and aggregation of misfolded proteins cause neurodegenerative disease, such as Alzheimer's disease (AD), Parkinson's disease (PD), and polyglutamine diseases [1, 2]. Polyglutamine diseases, including Huntington's disease (HD), dentatorubral-pallidoluysian atrophy, spinal and bulbal muscular atrophy, several types of spinocerebellar ataxias, and Huntington's disease-like 2 [3], are the result of the aggregation of misfolded mutant huntingtin (mHtt) proteins exhibiting more than 35 glutamine repeating units in diseased neurons [4, 5]. These mHtt proteins usually promote neuronal death when in the form of toxic multimeric complexes [6,7], although normal huntingtin (Htt) protein is important for neuronal function [8]. Among the polyglutamine diseases, HD is the most prevalent.

There are two main mechanistic pathways for proteolysis in eukaryotes, the ubiquitinproteasome system (UPS) and autophagy-lysosomal pathway (ALP) [9, 10]. Short-lived intracellular proteins are mainly removed by the UPS, whereas most long-lived proteins, misfolded proteins, protein aggregates, and damaged organelles are degraded by the ALP [11]. Aggregated mHtt proteins are inefficiently degraded by the proteasome due to their size; hence, they can be targeted for degradation by autophagy [3]. Autophagy is a lysosomebased evolutionarily conserved and dynamic intracellular process, in which cytoplasmic constituents are engulfed by autophagosomes and delivered to lysosomes for degradation [12]. Impaired autophagy can lead to abnormal protein aggregation and result in severe disease, such as AD, PD, and polyglutamine diseases [3, 13, 14]. However, upregulating autophagy by some small molecules and nanomaterials, such as trehalose, rapamycin, lithium, and europium hydroxide nanorods, may be useful for the treatment of these diseases [15-18].

To date, the choice of anesthetic during surgery in patients with polyglutamine diseases and evaluation of the effects and underlying mechanisms in these patients have rarely been reported [19]. Midazolam is a commonly used intravenous anesthetic for sedation and balanced general anesthesia during surgery, and it has been reported to be used in HD patients $[20,21]$. In the present study, we found that midazolam increased the accumulation of mHtt proteins in vitro, which was caused by the dysfunction of autopahgic degradation. However, through overexpression of cathepsin D, midazolam-impaired autophagic degradation was restored, and $\mathrm{mHtt}$ was degraded to relatively low levels, resulting in increased cell survival. Here, our results revealed the risk of accelerating the pathogenesis of polyglutamine diseases by midazolam and suggested that cathepsin $\mathrm{D}$ might be a candidate target for reduction of midazolam-dependent neurotoxicity.

\section{Materials and Methods}

\section{Antibodies and agents}

Anti-LC3 antibody (1:2000, NB100-2220) was purchased from Novus Biologicals (Littleton, CO); nti-SQSTM1/p62 antibody (1:2000, ab56416) was purchased from Abcam (Cambridge, UK); anti-RS6KB antibody (anti-p70 S6 kinase, 1:1000, 9202), anti-phosphorylated RS6KB antibody (anti-phospho-p70 S6kinase, 1:1000, 9205), anti-mTOR antibody $(1: 1000,2983)$, and anti-p-mTOR antibody $(1: 1000,2971)$ were purchased from Cell Signaling Technology (Danvers, MAA); nti-GAPDH antibody (1:10, 000, AB9132) was purchased from Merck Millipore (Darmstadt, Germany); anti-green fluorescent protein (GFP) antibody (1:1000, 66002-1-Ig) was purchased from Proteintech (Wuhan, China); anti-cathepsin D antibody (1:1000, sc-6486), anti-LAMP1 antibody (1:1000, sc-71489), and goat anti-rabbit IgG-FITC antibody (SC2-12, 1:100 dilution) were purchased from Santa Cruz Biotechnology (Dallas, TX). Horseradish peroxidase (HRP)conjugated anti-rabbit antibody (W4011), HRP-conjugated anti-goat antibody (V805A), and HRP-conjugated anti-mouse antibody (W4021) were purchased from Promega (Madison, WI). Chloroquine (CQ), Trehalose (T9531), and Hoechst 33342 (B2261) were purchased from Sigma-Aldrich (St. Louis, MO), cathepsin D plasmid was purchased from Sino Biological, Inc. (Beijing, China), enhanced chemiluminescence (ECL) 


\section{Cellular Physiology Cell Physiol Biochem 2018;48:683-691 \begin{tabular}{l|l} 
DOI: 10.1159/000491895 & $\begin{array}{l}\text { O } 2018 \text { The Author(s). Published by S. Karger AG, Basel } \\
\text { www.karger.com/cpb }\end{array}$
\end{tabular} \\ Zhang et al.: Midazolam Enhances Mutant Huntingtin Protein Accumulation}

kits were from Biological Industries (Kibbutz Beit HaEmek, Israel), lipofectamine 2000 (11668-019) was purchased from Invitrogen (Carlsbad, CA), and midazolam was provided by Jiangsu Nhwa Pharmaceutical Co., Ltd. (Xuzhuo, China).

\section{Cell culture}

Cells were cultured at $37^{\circ} \mathrm{C}$ with $5 \% \mathrm{CO}_{2}$ in Dulbecco's modified Eagle's medium supplemented with $10 \%$ fetal bovine serum (FBS). PC12 stable cells were transfected with GFP-tagged Htt (Q74) expression vectors using Lipofectamine 2000 and selected in medium containing $0.6 \mathrm{mg} / \mathrm{ml} \mathrm{G418.}$

\section{Cell viability assay}

Cells were seeded in 96 -well plates $\left(10^{4} /\right.$ well) and cultured at $37^{\circ} \mathrm{C}$ with $5 \% \mathrm{CO}_{2}$. Wild-type cells or cathepsin D-overexpressed cells were treated with $15 \mu \mathrm{M}$ midazolam for $48 \mathrm{~h}$. Then, $10 \mu \mathrm{l}$ MTT (5 mg/ml) was added to each well and incubated at $37^{\circ} \mathrm{C}$ for $4 \mathrm{~h}$. After removing the medium, formazan crystals were dissolved in $100 \mu \mathrm{l}$ DMSO, and the absorbance was measured at $570 \mathrm{~nm}$ using a microplate reader (Nano Quant, Tecan, Männedorf, Switzerland).

\section{Immunofluorescence}

Cells were fixed using 4\% paraformaldehyde for $10 \mathrm{~min}$, permeabilized with $0.1 \%$ Triton X-100 for $10 \mathrm{~min}$, and blocked with $1 \%$ FBS for $1 \mathrm{~h}$. Cells were incubated with the primary antibody overnight at $4{ }^{\circ} \mathrm{C}$ and labeled with the secondary antibody at $37^{\circ} \mathrm{C}$ for $1 \mathrm{~h}$. Images were acquired using an LSM 710 confocal microscope (Carl Zeiss AG, Oberkochen Germany.

\section{Western blotting}

Cells were lysed with sample buffer and boiled for $10 \mathrm{~min}$. Proteins were separated by sodium dodecyl sulfate polyacrylamide gel electrophoresis and were transferred onto nitrocellulose membranes. The membranes were incubated with the primary antibody at $4^{\circ} \mathrm{C}$ overnight and the second antibody for $1 \mathrm{~h}$ at $37^{\circ} \mathrm{C}$. Membranes were incubated with the ECL kit and visualized using a chemiluminescence instrument (ImageQuant LAS 4000, GE Healthcare, Little Chalfont, UK).

\section{Statistical analysis}

All data were expressed as the mean \pm SEM and analyzed by analysis of variance or two-tailed Student's t-tests. ${ }^{*} \mathrm{P}<0.05,{ }^{* *} \mathrm{P}<0.01$, and ${ }^{* * *} \mathrm{P}<0.001$ were considered statistically significant.

\section{Results}

\section{Midazolam induced GFP-Htt (Q74) accumulation}

GFP-Htt (Q74)-PC12 cells were generated from a PC12 cell line which stably expressed GFP-tagged Htt protein containing 74 glutamine repeating units. In these cells, GFP-Htt (Q74) protein was observed as bright punctate dots [22], indicating the formation of aggregates. As shown in Fig. 1a-d, midazolam increased the percentage of cells containing GFP-Htt (Q74) aggregates in a time- and dose-dependent manner. Further, the cytoplasmic mHtt protein levels were significantly increased following midazolam treatment at doses greater than 5 $\mu \mathrm{M}$ (Fig. 1e, g). Additionally, $15 \mu \mathrm{M}$ midazolam treatment significantly increased GFP-Htt (Q74) levels after $36 \mathrm{~h}$ (Fig. 1f, h). Collectively, our results showed that midazolam could induce mHtt accumulation in GFP-Htt (Q74)-PC12 cells.

\section{Role of autophagy in midazolam-induced GFP-Htt (Q74) accumulation}

As autophagy is the main pathway for $\mathrm{mHtt}$ protein degradation, we tested the role of autophagy in midazolam-treated cells. Trehalose and CQ are commonly used as an autophagy inducer and blocker, respectively $[18,23]$. Trehalose significantly attenuated the elevation of GFP-Htt (Q74) puncta following midazolam treatment, but CQ had the opposite effect (Fig. $2 \mathrm{a}, \mathrm{b})$. Furthermore, western blotting results showed that the level of GFP-Htt (Q74) was decreased following treatment with trehalose plus midazolam, compared with midazolam alone (Fig. 2c, e); by contrast, saturated CQ further increased GFP-Htt (Q74) accumulation 
Fig. 1. Midazolam induces GFP-Htt (Q74) accumulation. (a-d) Optical and fluorescence microscopy images of GFP-Htt (Q74)-PC12 cells. Cells were incubated with 0-30 $\mu \mathrm{M}$ midazolam for $0-60 \mathrm{~h}$. Scale bar: $50 \mu \mathrm{m}$. (e-h) Western blotting and quantification of GFP$\mathrm{Htt}$ (Q74) and $\beta$-actin; cells were treated with $0-30 \mu \mathrm{M}$ midazolam for $0-60 \mathrm{~h}$.

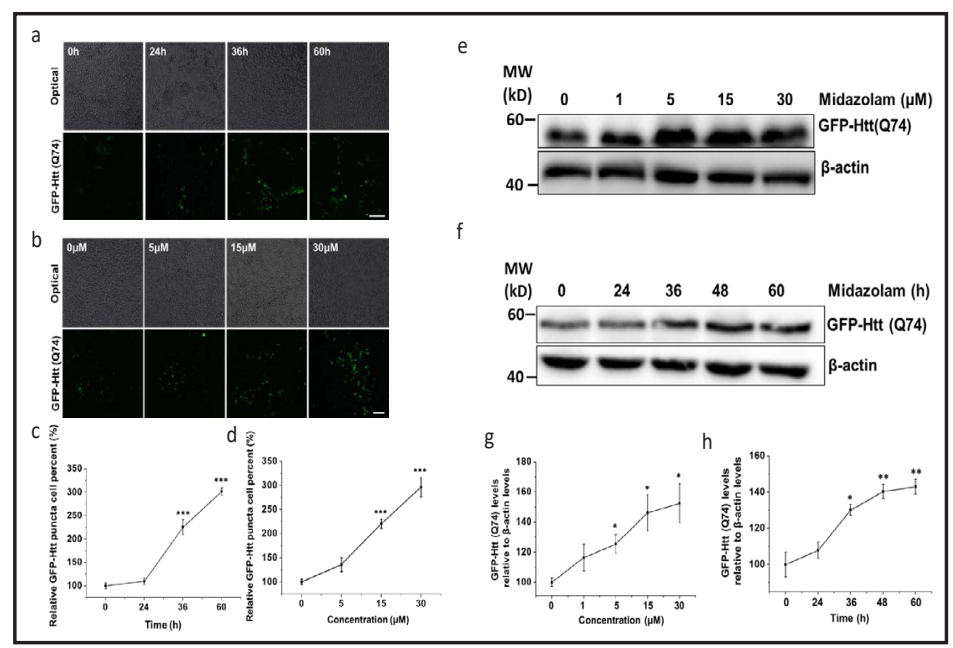

Fig. 2. Autophagy is involved in GFP-Htt (Q74) accumulation. (a, b) Optical and fluorescence microscopy images of GFP-Htt (Q74)-PC12 cells. Cells were treated with $15 \mu \mathrm{M}$ midazolam, $100 \mathrm{mM}$ trehalose, $50 \mu \mathrm{M}$ CQ (saturated CQ was added $4 \mathrm{~h}$ before measurement), $10 \mu \mathrm{M}$ MG132, midazolam plus trehalose, midazolam plus CQ and midazolam plus MG132 for $36 \mathrm{~h}$. Scale bar: $50 \mu \mathrm{m}$. (c-f) Western blotting and quantification of GFP-Htt (Q74) and $\beta$-actin. Cells were treated as in (a).

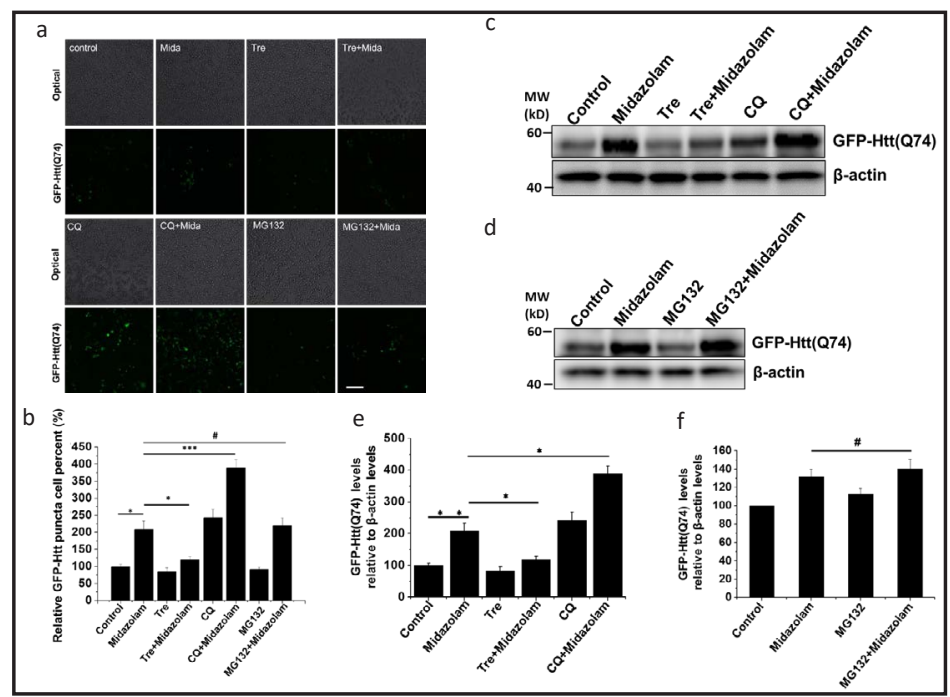

(Fig. 2c, e). These data demonstrate the important role of autophagy in midazolam-induced mHtt protein accumulation.

UPS, another important pathway for proteolysis in eukaryotes, could be inhibited by MG132 [22]. However, there was no significant change in the percentage of GFP-Htt (Q74) puncta or in GFP-Htt (Q74) protein levels between midazolam- and MG132 plus midazolamtreated cells (Fig. 2d, f). Taken together, these results suggest that ALP, rather than UPS, is involved in midazolam-elicited GFP-Htt (Q74) accumulation.

\section{Midazolam induced autophagy in the mTOR-dependent signaling pathway}

Next, autophagy induction in midazolam-treated cells was determined. During the autophagy process, the autophagy marker protein LC3 is cleaved from LC3 I into the lower molecular weight LC3 II and aggregates on autophagosome membranes [24]. Thus, using immunofluorescence staining, we found that midazolam and its positive control trehalose elicited large numbers of LC3 puncta (Fig. 3a), indicating the formation of autophagosomes. Additionally, LC3 II levels in the midazolam- and trehalose-treated cells were increased (Fig. $3 \mathrm{~b}$ ), further confirming the formation of autophagosomes. Autophagosomes fuse with several lysosomes to form autolysosomes, in which the autophagic contents are degraded. LAMP1, a lysosomal membrane protein, and structures with overlapping immunofluorescence staining for LAMP1 and LC3 were considered autolysosomes [25, 26]. As shown in Fig. 3c, LC3 and LAMP1 signals clearly overlapped, suggesting the formation of autolysosomes. mTOR is a 


\section{Cellular Physiology Cell Physiol Biochem 2018;48:683-691 \begin{tabular}{c|c|c|} 
DOI: 10.1159/000491895 & O 2018 The Author(s). Published by S. Karger AG, Basel \\
www.karger.com/cpb
\end{tabular} \\ Zhang et al.: Midazolam Enhances Mutant Huntingtin Protein Accumulation}

key molecule in the autophagy pathway, and protein S6 kinase (p70S6K) is its substrate $[27,28]$. Western blotting results showed that midazolam decreased the phosphorylation of mTOR and p70S6K (Fig. 3d). Together, these results demonstrated that midazolam induced autophagy in the mTOR-dependent signaling pathway in PC12 cells.

\section{Midazolam impaired autophagic degradation}

Accumulation of GFP-Htt (Q74) and enlarged autolysosomes (Fig. 3c) suggested the blockade of autophagic flux $[23,29]$; thus, we measured autophagic degradation. The effect of sequestosome 1 (SQSTM1/p62), a protein substrate that is selectively incorporated during the formation of autophagosomes and degraded by autophagy, was investigated first [30]. p62 levels were decreased with time in the positive control trehalose-treated cells, but significantly increased by midazolam (Fig. 4a, b), indicating a lack of degradation of p62. Although LC3 II is increased during the induction of autophagy, it is degraded and decreased for recycling at the late stage of autophagy [24]. However, midazolam treatment continued to increase LC3 II levels, in contrast to the positive control group (Fig. 4a, c). Next, levels of the lysosomal protease cathepsin D were measured. As shown in Fig. 4a and d, both the precursor and mature forms of cathepsin D were decreased after midazolam treatment for $24 \mathrm{~h}$, but there were no obvious changes in trehalose-treated cells, suggesting the disrupted function of autolysosomes.

Fig. 3. Midazolam induces autophagy in the mTOR-dependent signaling pathway. (a) Confocal images of immunofluorescence labeling for light chain 3 (LC3, green). The nucleus was stained with Hoechst stain. Scale bar: $20 \mu \mathrm{m}$. (b) Western blotting results of LC3 and $\beta$-actin; cells were treated with $15 \mu \mathrm{M}$ midazolam and trehalose for 36 h. (c) Confocal images of double immunofluorescence labeling for LC3 (green) and lysosomalassociated membrane protein 1 (LAMP1, red). Scale bar: $20 \mu \mathrm{m}$. (d) Western blotting results of

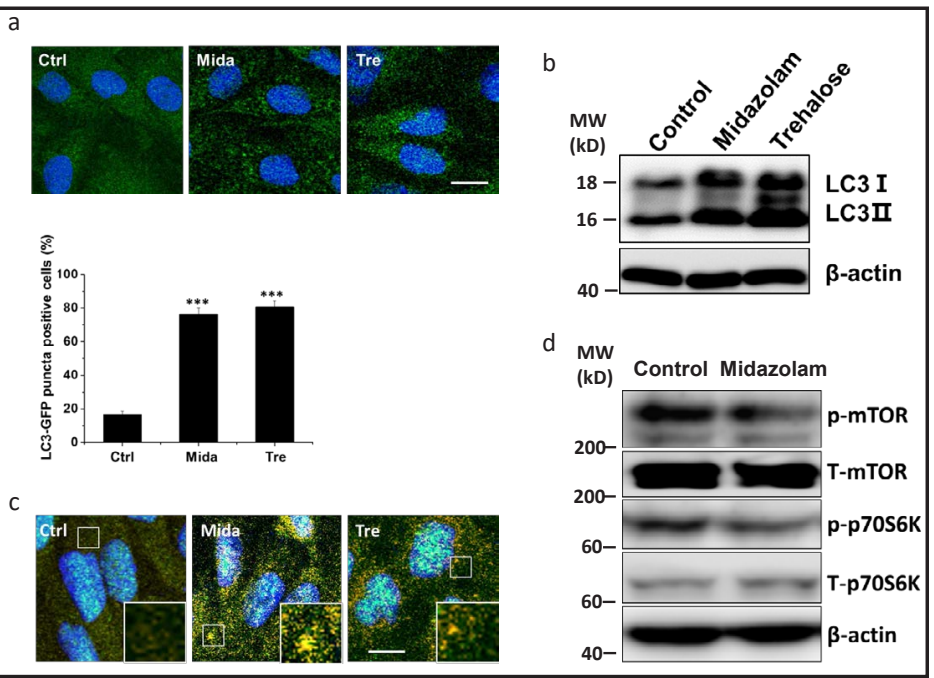
p-mTOR, total mTOR, p-p70s6k, total p70s6k, and $\beta$-actin. Cells were treated with $15 \mu \mathrm{M}$ midazolam for $36 \mathrm{~h}$.

Fig. 4. Midazolam impairs autophagic degradation. Western blotting results of p62, cathepsin D (Cath D), LC3, and $\beta$-actin. Cell were treated with $15 \mu \mathrm{M}$ midazolam or $100 \mathrm{mM}$ trehalose for $0-60 \mathrm{~h}$. Trehalose treatment was set as the positive control. (b-d) p62, Cath D, and LC3 levels relative to $\beta$-actin.

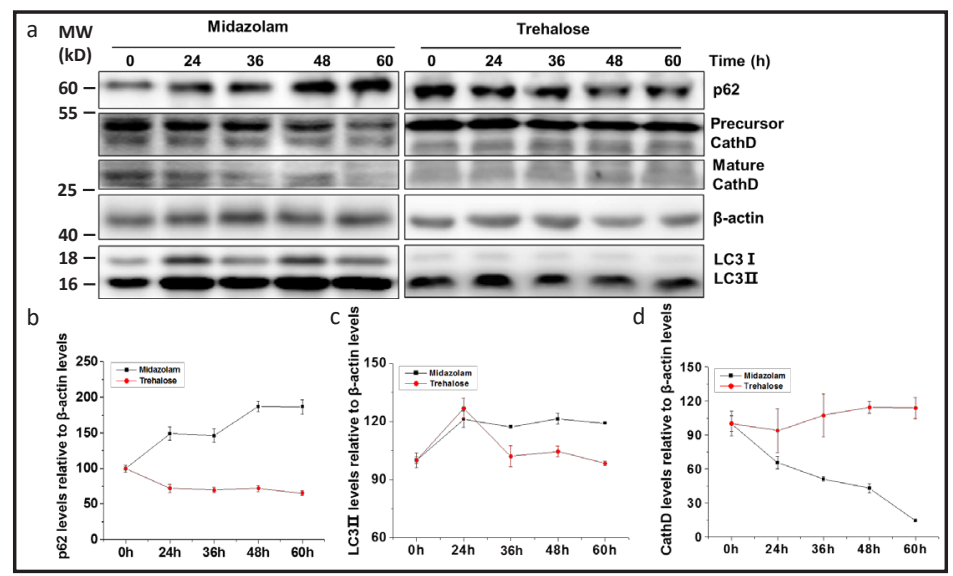




\section{Cellular Physiology Cell Physiol Biochem 2018;48:683-691 \begin{tabular}{l|l} 
DOI: 10.1159/000491895 & $\begin{array}{l}\text { O } 2018 \text { The Author(s). Published by S. Karger AG, Basel } \\
\text { www.karger.com/cpb }\end{array}$
\end{tabular}

Fig. 5. Overexpression of cathepsin D enhances Htt (Q74) degradation and promotes cell survival. (a-c) Western blotting and quantification of p62, cathepsin D (CathD), LC3, GFP-Htt (Q74), and $\beta$-actin. GFP-Htt (Q74)-PC12 cells or CathD-overexpressed cells were treated with $15 \mu \mathrm{M}$ midazolam for $36 \mathrm{~h}$. (d) Cell viability was detected by MTT assay. GFP-Htt (Q74)PC12 cells or CathD-overexpressed cells were treated with $15 \mu \mathrm{M}$ midazolam for $36 \mathrm{~h}$.

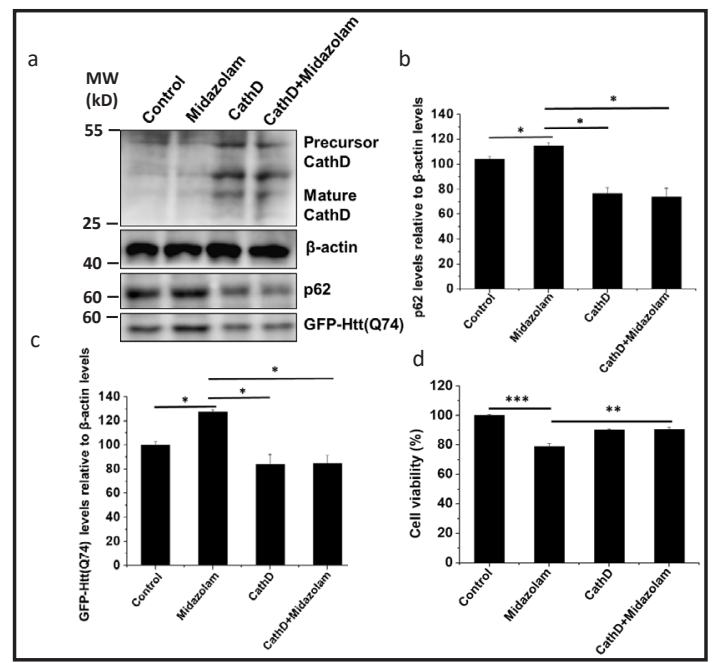

Fig. 6. Schematic illustration of the mechanism of midazolam-induced mHtt accumulation and cell toxicity via disruption of autolysosomes. Midazolam elicits autophagy initiation and autolysosome formation via the mTOR-dependent pathway in GFP-Htt (Q74)-PC12 cells. Furthermore, midazolam decreases cathepsin D levels and impairs the autolysosomes, leading to p62 and toxic $\mathrm{mHtt}$ accumulation. As a consequence, cell viability is affected. However, through overexpression of cathepsin D, midazolam-impaired autophagic degradation is restored, and $\mathrm{mHtt}$ is also degraded to relative low levels, resulting

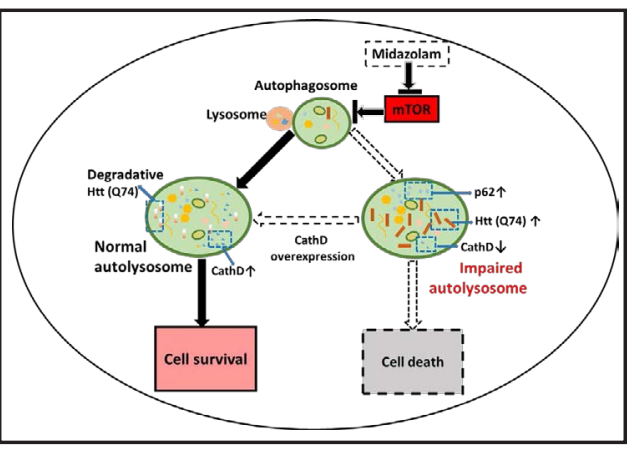

in increased cell survival.

Overexpression of cathepsin D enhanced GFP-Htt (Q74) degradation and promoted cell survival

Through overexpression of cathepsin D (Fig. 5a), we aimed to restore autophagic degradation. Indeed, the levels of p62 (Fig. 5a, b) and Htt (Q74) (Fig. 5a, c) were decreased during midazolam treatment in cathepsin D-overexpressed cells, suggesting normal autopahgic degradation. This further illustrates the important role of autophagy in polyglutamine diseases.

It has been well documented that aggregated mHtt protein is toxic to cells [31], and we found that midazolam led to a $20 \%$ decrease in GFP-Htt (Q74)-PC12 cell viability (Fig. 5d), but midazolam was not toxic in wild-type PC12 cells (data not show). Moreover, reduction of $\mathrm{mHtt}$ protein through cathepsin D overexpression could significantly restore cell viability (Fig. 5d), revealing that the toxicity of midazolam in GFP-Htt (Q74)-PC12 cells resulted from aggregated $\mathrm{mHtt}$. The proposed mechanism underlying the effect of midazolam on $\mathrm{mHtt}$ accumulatin and cell toxicity is shown schematically in Fig. 6.

\section{Discussion}

In this study, through fluorescence microscopy observations and western blotting results, we found that the commonly used intravenous anesthetic midazolam could increase intracellular mHtt, but other intravenous anesthetics, such as propofol and etomidate, had no effect (data not show). However, the elevation of mHtt may promote the pathological development of polyglutamine diseases, such as HD, as aggregated mHtt is toxic to cells 


\section{Cellular Physiology Cell Physiol Biochem 2018;48:683-691 \begin{tabular}{c|c|c} 
DOI: 10.1159/000491895 & O 2018 The Author(s). Published by S. Karger AG, Basel \\
www.karger.com/cpb
\end{tabular} \\ Zhang et al.: Midazolam Enhances Mutant Huntingtin Protein Accumulation}

[3]. Indeed, our MTT results showed that GFP-Htt (Q74)-PC12 cells are more vulnerable to midazolam compared with wild-type cells (data not show). Thus, our study revealed for the first time that an intravenous anesthetic increased the risk of accelerating the pathogenesis of polyglutamine diseases, indicating that midazolam may not be the anesthetic of choice for use in patients with these diseases.

The UPS and ALP pathways are two main mechanistic pathways for proteolysis in eukaryotes. In the present study, autophagy, an important biological degradative process, was shown to be the main pathway for mHtt degradation in midazolam-treated cells, as enhancing or blocking autophagic flux by trehalose or CQ could decrease or increase midazolam-induced elevation of $\mathrm{mHtt}$, respectively. Surprisingly, we found that midazolam could also induce autophagy in the mTOR-dependent signaling pathway, which should have decreased the intracellular mHtt levels. Further investigation showed that midazolam impaired autophagic degradation by inducing considerable non-functional autolysosome formation. Thus, accumulation of $\mathrm{mHtt}$ with autophagy induction in midazolam-treated cells is reasonable.

Autophagic degradation occurs in the autolysosome and is dependent on lysosomal proteases. However, in this study, cathepsins D, an important aspartate protease, was found to be decreased in midazolam-treated cells. Loss of cathepsin D in processing damaged or aggregated proteins has been demonstrated in neuronal cell death and neurological disorders [31-34], consistent with our results. Furthermore, mHtt degradation and cell viability were enhanced though overexpression of cathepsin D, suggesting that cathepsin D may be a target for reduction of midazolam-induced neurotoxicity and treatment of polyglutamine diseases.

This study was conducted in transgenic cells in vitro, which could be used for the simultaneous high-throughput detection of toxicity of various anesthetics in different diseases $[35,36]$. Furthermore, this model is time-efficient and economical for intensive study of molecular mechanisms and for investigating drug targets for various disease [37]. However, in vitro cell experiments are unilateral, and they cannot completely simulate the pathological process in vivo. Thus, the effect and mechanism of action of midazolam in polyglutamine diseases should be further investigated in vivo.

In summary, midazolam-induced dysfunctional autophagy contributed to the accumulation of mHtt in PC12-Q74 cells, and the aggregated $\mathrm{mHtt}$ may responsible for the toxicity of midazolam. Cathepsin D may be a candidate target for reduction of this neurotoxicity, and our results revealed the risk of accelerating the pathogenesis of HD or polyglutamine diseases by midazolam.

\section{Acknowledgements}

This work was supported by grants from the National Natural Science Foundation of China (81701073, 81171031, 81571039, 81770298, 81500949, 81401518, 81601600) and Key Projects of Natural Science Research in Anhui Colleges and Universities (KJ2017A193, KJ2018A0189).

\section{Disclosure Statement}

No potential conflicts of interest were disclosed.

\section{References}

\footnotetext{
1 Taylor JP, Hardy J, Fischbeck KH: Toxic proteins in neurodegenerative disease. Science 2002;296:19911995.
} 


\section{Cellular Physiology Cell Physiol Biochem 2018;48:683-691 \begin{tabular}{l|l} 
and Biochemistry Published online:July 19, 2018 & $\begin{array}{l}\text { D) } 2018 \text { The Author(s). Published by S. Karger AG, Basel } \\
\text { www.karger.com/cpb }\end{array}$ \\
\hline
\end{tabular}}

Zhang et al.: Midazolam Enhances Mutant Huntingtin Protein Accumulation

-2 Martinez-Vicente M, Cuervo AM: Autophagy and neurodegeneration: when the cleaning crew goes on strike. Lancet Neurol 2007;6:352-361.

3 Jimenez-Sanchez M, Thomson F, Zavodszky E, Rubinsztein DC: Autophagy and polyglutamine diseases. Prog Neurobiol 2012;97:67-82.

4 Perutz MF, Windle AH: Cause of neural death in neurodegenerative diseases attributable to expansion of glutamine repeats. Nature 2001;412:143-144.

-5 Sinden RR: Neurodegenerative diseases. Origins of instability. Nature 2001;411:757-758.

6 Sarkar S, Rubinsztein DC: Small molecule enhancers of autophagy for neurodegenerative diseases. Mol Biosyst 2008;4:895-901.

-7 Tsunemi T, Ashe TD, Morrison BE, Soriano KR, Au J, Roque RA, Lazarowski ER, Damian VA, Masliah E, La Spada AR: PGC-1alpha rescues Huntington's disease proteotoxicity by preventing oxidative stress and promoting TFEB function. Sci Transl Med 2012;4:142ra197.

8 Cattaneo E, Zuccato C, Tartari M: Normal huntingtin function: an alternative approach to Huntington's disease. Nat Rev Neurosci 2005;6:919-930.

9 Mizushima N, Levine B, Cuervo AM, Klionsky DJ: Autophagy fights disease through cellular self-digestion. Nature 2008;451:1069-1075.

10 Bence NF, Sampat RM, Kopito RR: Impairment of the ubiquitin-proteasome system by protein aggregation. Science 2001;292:1552-1555.

11 Lamark T, Johansen T: Aggrephagy: selective disposal of protein aggregates by macroautophagy. Int J Cell Biol 2012;2012:736905.

12 Xie Z, Klionsky DJ: Autophagosome formation: core machinery and adaptations. Nat Cell Biol 2007;9:11021109.

13 Pan T, Kondo S, Le W, Jankovic J: The role of autophagy-lysosome pathway in neurodegeneration associated with Parkinson's disease. Brain 2008;131:1969-1978.

14 Boland B, Kumar A, Lee S, Platt FM, Wegiel J, Yu WH, Nixon RA: Autophagy induction and autophagosome clearance in neurons: relationship to autophagic pathology in Alzheimer's disease. J Neurosci 2008;28:6926-6937.

15 Sarkar S, Davies JE, Huang Z, Tunnacliffe A, Rubinsztein DC: Trehalose, a novel mTOR-independent autophagy enhancer, accelerates the clearance of mutant huntingtin and alpha-synuclein. J Biol Chem 2007;282:5641-5652.

16 Rubinsztein DC, Gestwicki JE, Murphy LO, Klionsky DJ: Potential therapeutic applications of autophagy. Nat Rev Drug Discov 2007;6:304-312.

17 Sarkar S, Floto RA, Berger Z, Imarisio S, Cordenier A, Pasco M, Cook LJ, Rubinsztein DC: Lithium induces autophagy by inhibiting inositol monophosphatase. J Cell Biol 2005;170:1101-1111.

18 Wei PF, Jin PP, Barui AK, Hu Y, Zhang L, Zhang JQ Shi SS, Zhang HR, Lin J, Zhou W, Zhang YJ, Ruan RQ, Patra CR, Wen LP: Differential ERK activation during autophagy induced by europium hydroxide nanorods and trehalose: Maximum clearance of huntingtin aggregates through combined treatment. Biomaterials 2015;73:160-174.

19 Wang Q, Liang G, Yang H, Wang S, Eckenhoff MF, Wei H: The common inhaled anesthetic isoflurane increases aggregation of huntingtin and alters calcium homeostasis in a cell model of Huntington's disease. Toxicol Appl Pharmacol 2011;250:291-298.

20 Rodrigo MR: Huntington's chorea: midazolam, a suitable induction agent? Br J Anaesth 1987;59:388-389.

-21 Mitra S, Sharma K, Arora S, Deva C, Gombar KK: Repeat anesthetic management of a patient with Huntington's chorea. Can J Anaesth 2001;48:933-934.

22 Jin P, Wei P, Zhang Y, Lin J, Sha R, Hu Y, Zhang J, Zhou W, Yao H, Ren L, Yang JY, Liu Y, Wen L: Autophagymediated clearance of ubiquitinated mutant huntingtin by graphene oxide. Nanoscale 2016;8:1874018750.

23 Zhang JQ, Zhou W, Zhu SS, Lin J, Wei PF, Li FF, Jin PP, Yao H, Zhang YJ, Hu Y, Liu YM, Chen M, Li ZQ, Liu XS, Bai L, Wen LP: Persistency of Enlarged Autolysosomes Underscores Nanoparticle-Induced Autophagy in Hepatocytes. Small 2017;13. Doi: 10.1002/smll.201602876

-24 Ni HM, Bockus A, Wozniak AL, Jones K, Weinman S, Yin XM, Ding WX: Dissecting the dynamic turnover of GFP-LC3 in the autolysosome. Autophagy 2011;7:188-204.

25 Zhang J, Zhou W, Lin J, Wei P, Zhang Y, Jin P, Chen M, Man N, Wen L: Autophagic lysosomal reformation depends on mTOR reactivation in H2O2-induced autophagy. Int J Biochem Cell Biol 2016;70:76-81. 


\section{Cellular Physiology Cell Physiol Biochem 2018;48:683-691 \begin{tabular}{l|l} 
DOI: 10.1159/000491895 & $\begin{array}{l}\text { O 2018 The Author(s). Published by S. Karger AG, Basel } \\
\text { www.karger.com/cpb }\end{array}$
\end{tabular} \\ Zhang et al.: Midazolam Enhances Mutant Huntingtin Protein Accumulation}

-26 Yu L, McPhee CK, Zheng L, Mardones GA, Rong Y, Peng J, Mi N, Zhao Y, Liu Z, Wan F, Hailey DW, Oorschot V, Klumperman J, Baehrecke EH, Lenardo MJ: Termination of autophagy and reformation of lysosomes regulated by mTOR. Nature 2010;465:942-946.

27 Ravikumar B, Vacher C, Berger Z, Davies JE, Luo S, Oroz LG, Scaravilli F, Easton DF, Duden R, O’Kane CJ, Rubinsztein DC: Inhibition of mTOR induces autophagy and reduces toxicity of polyglutamine expansions in fly and mouse models of Huntington disease. Nat Genet 2004;36:585-595.

-28 Sarkar S, Ravikumar B, Floto RA, Rubinsztein DC: Rapamycin and mTOR-independent autophagy inducers ameliorate toxicity of polyglutamine-expanded huntingtin and related proteinopathies. Cell Death Differ 2009;16:46-56.

-29 Bordi M, Berg MJ, Mohan PS, Peterhoff CM, Alldred MJ, Che S, Ginsberg SD, Nixon RA: Autophagy flux in CA1 neurons of Alzheimer hippocampus: Increased induction overburdens failing lysosomes to propel neuritic dystrophy. Autophagy 2016;12:2467-2483.

-30 Bjorkoy G, Lamark T, Brech A, Outzen H, Perander M, Overvatn A, Stenmark H, Johansen T: p62/SQSTM1 forms protein aggregates degraded by autophagy and has a protective effect on huntingtin-induced cell death. J Cell Biol 2005;171:603-614.

-31 Liang Q, Ouyang X, Schneider L, Zhang J: Reduction of mutant huntingtin accumulation and toxicity by lysosomal cathepsins D and B in neurons. Mol Neurodegener 2011;6:37.

-32 Schneider L, Zhang J: Lysosomal function in macromolecular homeostasis and bioenergetics in Parkinson's disease. Mol Neurodegener 2010;5:14.

-33 Mueller-Steiner S, Zhou Y, Arai H, Roberson ED, Sun B, Chen J, Wang X, Yu G, Esposito L, Mucke L, Gan L: Antiamyloidogenic and neuroprotective functions of cathepsin B: implications for Alzheimer's disease. Neuron 2006;51:703-714.

-34 Cullen V, Lindfors M, Ng J, Paetau A, Swinton E, Kolodziej P, Boston H, Saftig P, Woulfe J, Feany MB, Myllykangas L, Schlossmacher MG, Tyynela J: Cathepsin D expression level affects alpha-synuclein processing, aggregation, and toxicity in vivo. Mol Brain 2009;2:5.

-35 Yang H, Liang G, Hawkins BJ, Madesh M, Pierwola A, Wei H: Inhalational anesthetics induce cell damage by disruption of intracellular calcium homeostasis with different potencies. Anesthesiology 2008;109:243250.

-36 Chang YC, Hsu YC, Liu CL, Huang SY, Hu MC, Cheng SP: Local anesthetics induce apoptosis in human thyroid cancer cells through the mitogen-activated protein kinase pathway. PLoS One 2014;9:e89563.

-37 Jan E, Byrne SJ, Cuddihy M, Davies AM, Volkov Y, Gun’ko YK, Kotov NA: High-content screening as a universal tool for fingerprinting of cytotoxicity of nanoparticles. ACS nano 2008;2:928-938. 